\title{
SYMPATHETIC POSTGANGLIONIC CHOLINERGIC FIBRES
}

\author{
BY \\ J. H. BURN AND M. J. RAND \\ From the Department of Pharmacology, University of Oxford
}

(RECEIVED JULY 27, 1959)

\begin{abstract}
When the postganglionic fibres to the nictitating membrane are stimulated in a cat treated with reserpine, the membrane contracts. The contraction is increased after the injection of eserine and is abolished with atropine. Thus the fibres stimulated appear to be cholinergic. When the splenic nerve is stimulated in a cat treated with reserpine there is similar evidence of the presence of cholinergic fibres; the spleen dilates, the dilatation is greater in the presence of eserine and is abolished by atropine. The hypogastric nerves when stimulated cause inhibition of the uterus of the virgin cat. When the cat is treated with reserpine, stimulation then causes contraction which is increased in the presence of eserine and abolished by atropine. There is also evidence of cholinergic fibres in the postganglionic supply to the vessels of the rabbit's ear. From this and other evidence it is suggested that a form of adrenergic mechanism may exist such that cholinergic fibres in the postganglionic sympathetic supply liberate acetylcholine; this in turn liberates noradrenaline from a store around the sympathetic nerve ending.
\end{abstract}

Many effects produced in the body by stimulation of sympathetic nerves are also produced by acetylcholine (after atropine) and by nicotine acting peripherally. Vasoconstriction in the vessels of the isolated and perfused rabbit ear is an example. Since these effects of acetylcholine and of nicotine disappear (a) after treatment of the animal with reserpine and (b) after degeneration of the sympathetic nerves, it seemed that the effects might actually be mediated through some part of the sympathetic mechanism. Cholinergic fibres have been shown to occur in various sympathetic nerves, the first demonstration of them having been made by Euler and Gaddum (1931).

We have therefore carried out an investigation to see if fibres liberating acetylcholine were present in postganglionic sympathetic nerves generally, and have studied the supply to the nictitating membrane, the spleen, the uterus of the nonpregnant cat and the perfused rabbit ear. Bacq and Fredericq (1935) had already given evidence for the presence of cholinergic fibres in the nictitating membrane. We thought that if sympathetic nerves in general contained cholinergic fibres, the acetylcholine liberated might then have the same effect as injected acetylcholine or nicotine.

\section{METHODS}

Our method has been to study the effect of stimulating postganglionic sympathetic fibres in cats or rabbits treated with reserpine. This treatment reduces or removes the store of noradrenaline present around the sympathetic nerve endings and makes it easier to see effects which might be produced by release of acetylcholine.

Reserpine was dissolved in a $20 \%$ solution of ascorbic acid, and usually a $1 \%$ solution was prepared which was injected into the peritoneal cavity on two successive days. The animal was used for the experiment on the third day. The amount injected was $1.5 \mathrm{mg} . / \mathrm{kg}$. on each day. The animals were kept in a warm room at a temperature of $27^{\circ}$.

For observations on the nictitating membrane, the cat was anaesthetized with chloralose. The superior cervical ganglion was exposed on one side and a pair of electrodes was applied so that one was in contact with the ganglion and the other just beyond. The contractions of the nictitating membrane were recorded by an isotonic lever.

For observations on the spleen the cat was partially eviscerated from the colon to the middle of the duodenum. the inferior and superior mesenteric arteries being divided. The fibres of the splenic nerve were identified near the origin of the splenic artery and a ligature was tied around them. The fibres were not cut. A pair of shielded electrodes could then be placed so as to stimulate them. An incision was made in the skin on the left side and the muscle layers were separated by retraction with two aneurysm needles so that the spleen could be brought out of the body cavity and put into a plethysmograph (Burn, 1952). The volume changes were recorded by a piston recorder.

For observations on the uterus, the cat was eviscerated and the ligament between the kidney and the ovary was divided on one side. A thread was attached to the ovary and passed over pulleys to a 

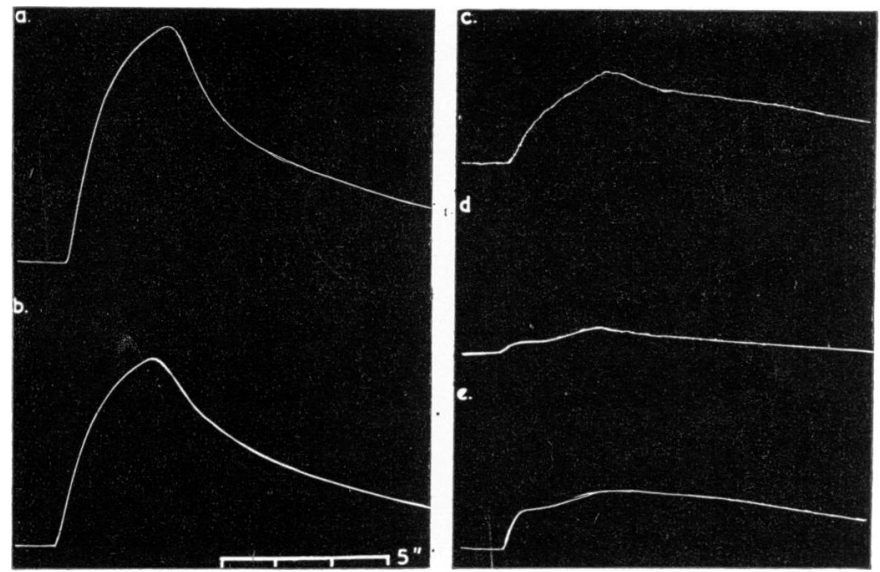

FIG. 1.-Contractions of nictitating membrane in response to postganglionic stimulation. (a) In normal cat, $(b)$ in same cat after $4 \mathrm{mg} . / \mathrm{kg}$. atropine, $(c)$ in cat treated with reserpine, $(d)$ in same cat after $4 \mathrm{mg} . / \mathrm{kg}$. atropine, $(e)$ in same cat after infusion of $0.5 \mathrm{mg}$. noradrenaline.

lever which recorded on the kymograph. The hypogastric nerves were identified and were passed through electrodes of a pattern recently described (Burn and Rand, 1960) which provided for a constant flow of oxygenated Krebs solution over the portion of nerve stimulated.

For observations on the perfused rabbit ear we used the preparation described by Gaddum and Kwiatkowski (1938) in which we applied electrodes to the fibres leaving the superior cervical ganglion. We also used the isolated ear, stimulating the mixed nerve at the base of the ear, using the perfusion system described by Burn (1952). For stimulation, the nerve was carefully dissected from its bed for about $7 \mathrm{~mm}$. leaving both the central and the distal part undissected to keep the nerve in place. A pair of electrodes were placed around the dissected portion. Stimulation in all experiments was by square wave pulses usually of $2 \mathrm{msec}$. duration at a frequency of 25 per sec. The strength of stimulus was usually $1 \mathrm{~mA}$. For observations on the pilomotor response to sympathetic stimulation in the cat's tail, cats were anaesthetized with chloralose and eviscerated to facilitate access to the lumbar sympathetic chain. We perfused the tail with Locke solution containing 4.5 g./1. sucrose at $35^{\circ}$, inserting the arterial cannula into the internal iliac artery of one side pointing towards the bifurcation; we tied the internal iliac of the other side and aorta just above the origin of the internal iliacs; thus the perfusing fluid passed into the caudal stump of the aorta. We stimulated the right lumbar sympathetic chain.

\section{RESULTS}

Nictitating Membrane.-In a previous paper (Burn and Rand, 1958b) we observed that when a cat had been treated with reserpine, although a large dose of tyramine failed to cause contraction of the nictitating membrane, stimulation of the postganglionic fibres was still able to do so. In Fig. 1 the effect of atropine on the contractions following sympathetic stimulation is shown. In a normal cat, the contraction was only slightly reduced by atropine even in the large dose of $4 \mathrm{mg}$. $/ \mathrm{kg}$., but in a cat treated with reserpine it was very greatly reduced by this dose. In this cat the contraction increased after an intravenous infusion of $0.5 \mathrm{mg}$. noradrenaline.

Fig. 2 taken from an experiment in a cat treated with reserpine shows that eserine, given in two injections of 0.1 mg. each, augmented the contractions caused by sympathetic stimulation, especially those of weaker stimuli, and that atropine in a dose of $4 \mathrm{mg}$. (=1.5 mg./ kg.) abolished the contractions. In two other experiments the effects of eserine and atropine were similar; in both, the effects of weaker stimuli were abolished by atropine and those of stronger stimuli greatly reduced. The threshold strength of stimulation was determined in three experiments and was found to be $0.39 \mathrm{~mA}$., $0.075 \mathrm{~mA}$.

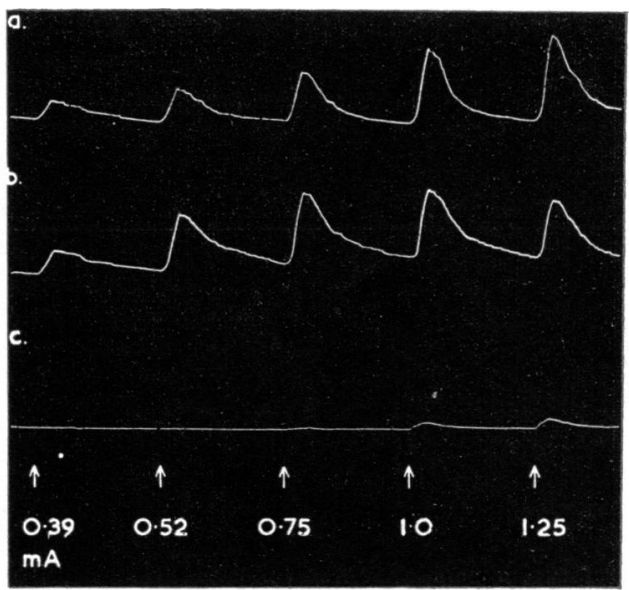

FIG. 2.-Contractions of nictitating membrane in response to postganglionic stimulation in cat treated with reserpine. (a) Responses to increasing strengths of stimulation as shown below, (b) increased responses after the injection of $0.2 \mathrm{mg}$. eserine, $(c)$ responses abolished after the injection of $1.5 \mathrm{mg} . / \mathrm{kg}$. atropine. 
FIG. 3.-Spleen volume and blood pressure in cat treated with reserpine. Stimulation of splenic nerves for $30 \mathrm{sec}$. with strength $3 \mathrm{~mA}$. caused small contraction of the spleen, and intravenous injection of $5 \mu \mathrm{g}$. acetylcholine caused dilatation followed by small slow contraction.

and $0.31 \mathrm{~mA}$. ; the threshold strength in one experiment on a normal cat was $0.25 \mathrm{~mA}$.

Spleen.-Stimulation of the splenic nerve caused contraction of the spleen as shown in Fig. 3, in which the B.P. observation was made in a cat treated $\mathrm{mm}$. with reserpine. The effect was much $\mathrm{Hg}_{100}$ smaller than that seen in a normal cat, but complete abolition of the contraction by reserpine treatment was rarely obtained. Fig. 3 also shows that in a cat treated with reserpine the intravenous injection of $5 \mu \mathrm{g}$. acetylcholine caused dilatation of the spleen, followed, as the blood pressure recovered, by a slight constriction. The stimulation of any cholinergic

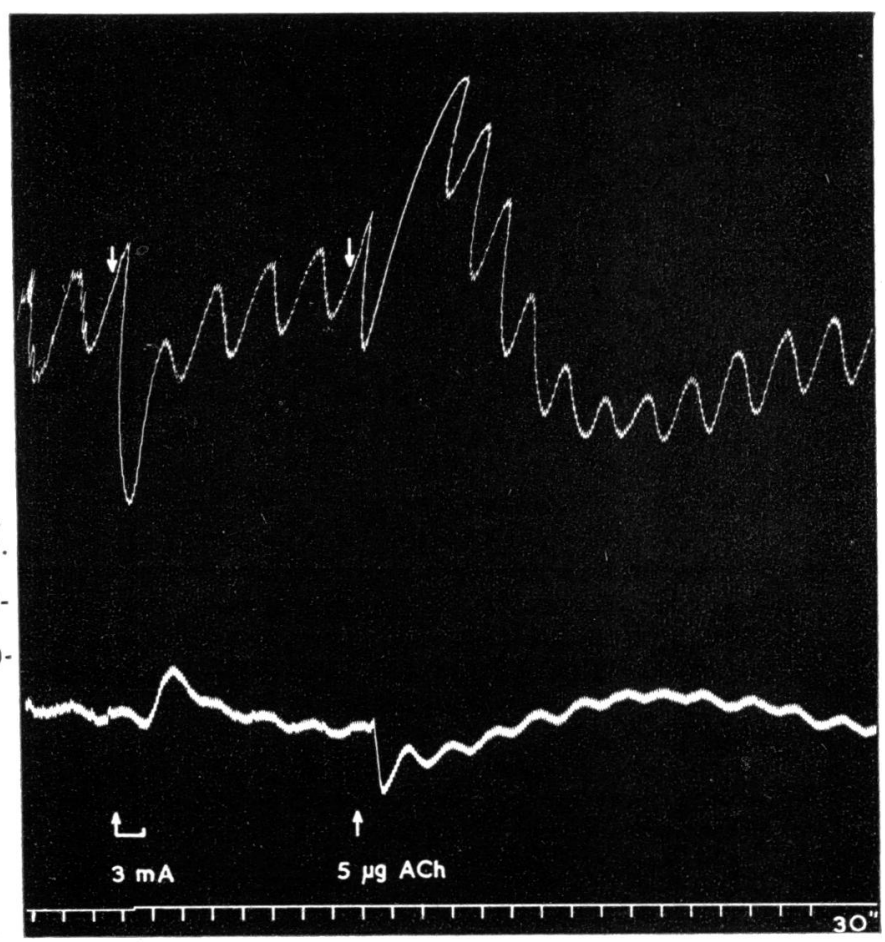

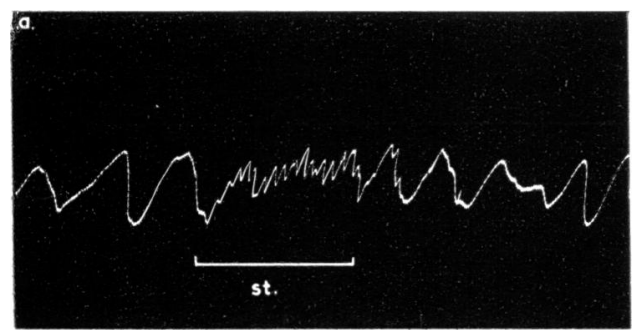

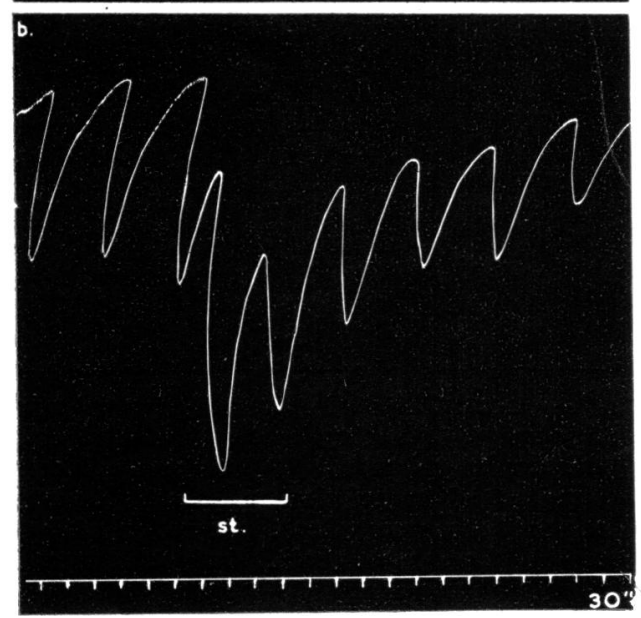

fibres which might be present in the splenic nerve would be expected to cause dilatation of the spleen, and would oppose the constrictor action of released noradrenaline.

Such a balance of opposed effects would explain the observations recorded in Fig. 4, also made in a cat treated with reserpine; at first stimulation caused no appreciable volume change but altered the record during the period of application, so that there were many small waves. Then $1 \mathrm{mg}$. atropine was injected, and $4 \mathrm{~min}$. later stimulation was repeated and a constrictor action was recorded, as if the injection of atropine had excluded the dilator effect of acetylcholine which initially masked the constrictor effect.

In one experiment recorded in Fig. 5, in a cat which was treated with reserpine, the effect of sympathetic stimulation was to produce dilatation of the spleen. An injection of eserine was then given and a repetition of the stimulation caused a

FIG. 4.-Spleen volume of cat treated with reserpine. (a) Stimulation of splenic nerves in presence of eserine caused a series of small waves, but had no general effect on the volume. (b) The same stimulation after the injection of $1 \mathrm{mg}$. atropine caused contraction of the spleen. 
FiG. 5.-Spleen volume of cat treated with reserpine. (a) Stimulation of splenic nerves for $30 \mathrm{sec}$. caused dilatation of the spleen. (b) After the injection of $0.35 \mathrm{mg}$. eserine, stimulation for 30 sec. caused a greater dilatation. (c) Stimulation for $60 \mathrm{sec}$. caused still greater dilatation. (d) Stimulation for 60 sec. after $1.3 \mathrm{mg} . / \mathrm{kg}$. atropine had no effect. (e) Stimulation for $60 \mathrm{sec}$. after infusion of $0.25 \mathrm{mg}$. noradrenaline caused a very slight contraction.


rather larger dilatation. Stimulation was then applied for twice as long, causing a much larger dilatation. An injection of $4 \mathrm{mg}$. atropine was then given and $3 \mathrm{~min}$. later stimulation had no effect. These were the principal observations, after which an infusion of $0.25 \mathrm{mg}$. noradrenaline was given. A further stimulation then caused a very slight constriction. An injection of tyramine which previously had no action caused a large constriction.

In other experiments of this kind in cats which were treated with reserpine, stimulation of the fibres of the splenic nerve caused a small constriction even in the presence of eserine ; it was, however, regularly observed that after the injection of $1 \mathrm{mg}$. atropine the constrictor response became 2 or 3 times greater than before.

Non-pregnant Cat Uterus. - Since the sympathetic innervation of the cat uterus when
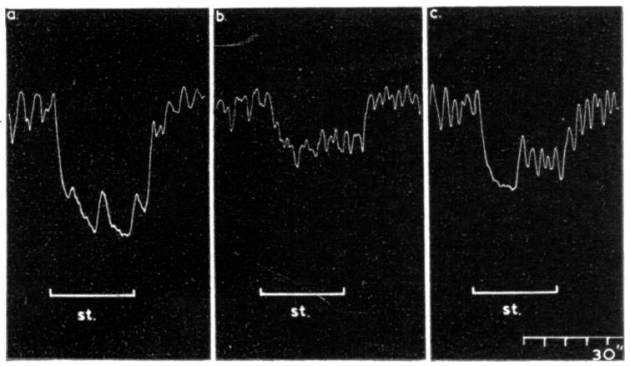

FIG. 6.-Uterus of virgin cat. (a) Stimulation of hypogastric nerves caused inhibition. (b) After injection of $0.3 \mathrm{mg}$. eserine the inhibition was reduced. (c) After the injection of $1 \mathrm{mg}$. $/ \mathrm{kg}$. atropine the inhibition was increased. virgin or non-pregnant is inhibitory, observations were first made in normal cats and later in cats treated with reserpine. Fig. 6 is taken from an experiment in a normal virgin cat, and shows the inhibition due to stimulation of the hypogastric nerves. Eserine was then injected intravenously in three doses of $0.1 \mathrm{mg}$. at intervals of $5 \mathrm{~min}$., and the stimulation was repeated. As a result the inhibition was diminished. Atropine was then injected in two doses each of $1 \mathrm{mg}$., and the stimulation was applied again; the inhibitory effect was then greater.

In observations on virgin cats treated with reserpine, the inhibitory effect was absent as shown in Fig. 7. Stimulation of the hypogastric nerves caused a small contraction, which was augmented in the presence of eserine. Atropine was then injected, and stimulation no longer caused contraction, but a very slight relaxation. An intravenous injection of $0.5 \mu \mathrm{g}$. adrenaline caused relaxation. These results in the cat treated with reserpine were observed in 4 experiments.

An observation was also made on the isolated horn of the uterus of a normal virgin bitch; it was found that acetylcholine caused contraction, but that in the presence of atropine it caused inhibition.

Perfused Rabbit Ear. - When perfusing the rabbit ear we did not find it easy to abolish the constrictor response to sympathetic stimulation by giving reserpine beforehand. Using the GaddumKwiatkowski method we observed, however, that the effect of sympathetic stimulation was increased by adding eserine $(5 \mu \mathrm{g} . / \mathrm{ml}$.) to the perfusing fluid. With Thorp's recorder it was possible to determine the volume of fluid (in drops) by which 


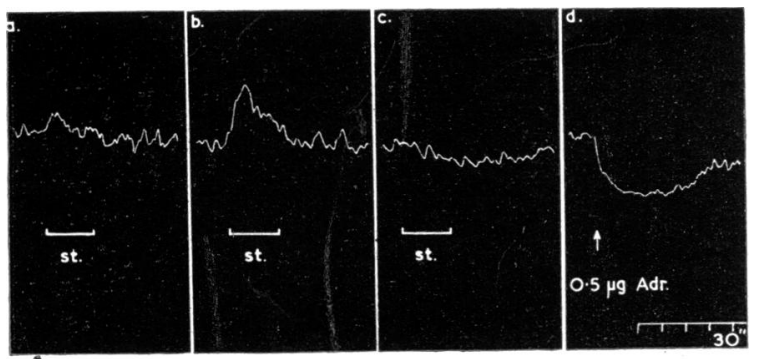

FIG. 7.-Uterus of virgin cat treated with reserpine. (a) Stimulation of hypogastric nerves caused slight contraction. (b) After injection of 0.3 mg. eserine, stimulation caused a greater contraction. ( ) After the injection of $1 \mathrm{mg}$. atropine, stimulation caused a very slight relaxation. (d) Injection of $0.5 \mu \mathrm{g}$. adrenaline caused relaxation.

sympathetic stimulation, for a given time, reduced the outflow. Thus in one experiment the outflow was reduced by 330 drops in a first period of stimulation and by 356 drops in a second. Eserine was then added to the perfusion fluid and sympathetic stimulation then reduced the outflow
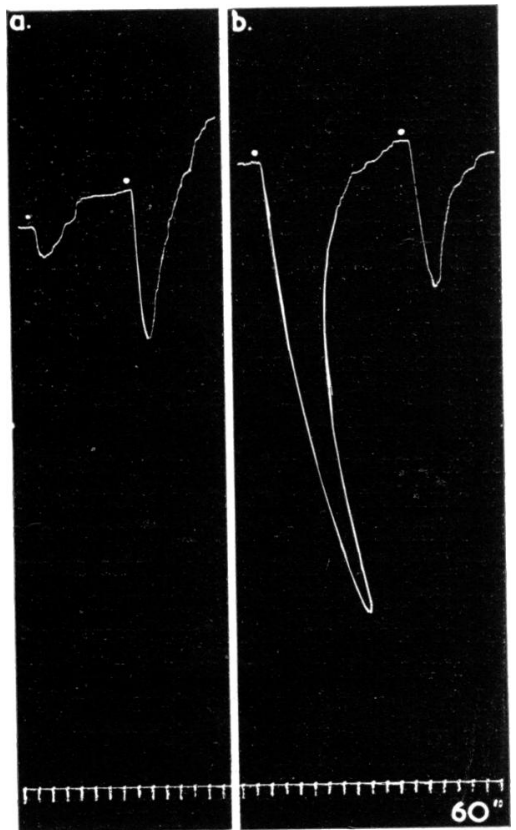

FIG. 8.-Record of outflow from rabbit ear during perfusion with Locke solution. (a) Stimulation of mixed nerve at the base of the ear for 10 sec. and then for $20 \mathrm{sec}$. caused slight reductions in outflow $(5 \mathrm{~mm}$. and $24 \mathrm{~mm}$. on drum). (b) Stimulation $15 \mathrm{~min}$. after eserine $(2 \mu \mathrm{g}$. ml.) was added to the perfusion fluid, the duration of stimulation being respectively $20 \mathrm{sec}$. and 10 sec., caused larger reductions in outflow $(75 \mathrm{~mm}$. and $25 \mathrm{~mm}$. on drum). by 486 drops. Similar observations were made in the isolated ear perfused through a cannula tied in the central artery at the base of the pinna. Fig. 8 shows the fall in outflow during stimulation of the mixed nerve, which was much greater after the addition of $3 \mu \mathrm{g} . / \mathrm{ml}$. eserine to the perfusion fluid.

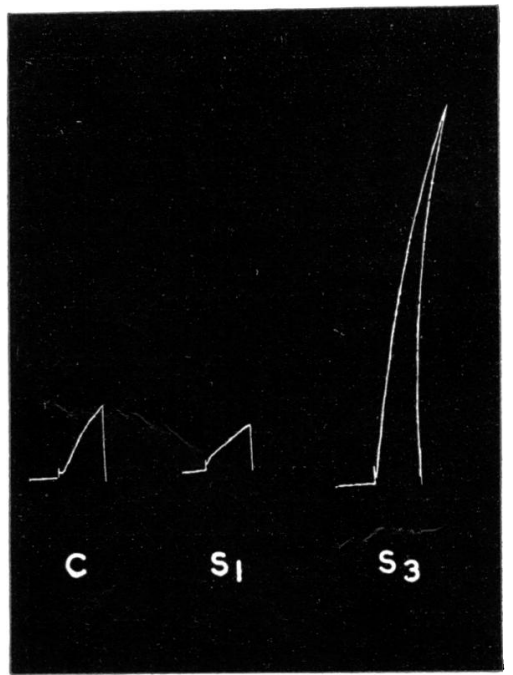

FIG. 9.-Tests of venous effluent from rabbit ear vessels on eserinized leech muscle. Perfusion with Locke solution containing eserine $5 \mu \mathrm{g} . / \mathrm{ml}$. At (C), effect of effluent before stimulation. At $\left(S_{1}\right)$ effect of effluent during stimulation for 1 min. At $\left(\mathrm{S}_{3}\right)$ effect of effluent collected during the third min. after stimulation.

Using the Gaddum-Kwiatkowski perfusion we collected the venous effluent and tested it on the leech. Fig. 9 shows that samples collected after stimulation had a stimulant action on the leech muscle. Similar positive results were obtained in 5 experiments. 
Block at Postganglionic Terminations. - We confirmed the observation of Brücke (1935) that, when a large amount of acetylcholine or of nicotine was injected into the skin at the base of a tuft of hair of the cat's tail, the effect of stimulation of the lumbar sympathetic chain was blocked, so that, while the adjacent tufts, respectively nearer to and further from the base of the tail, were erected during stimulation, the tuft at the site of injection remained unaffected. Fig. 10 gives an example of this action. A similar picture for nicotine is shown in Fig. 11.

These clear results were not obtained in all experiments, for the injection of nicotine or of acetylcholine not only blocked the effect of

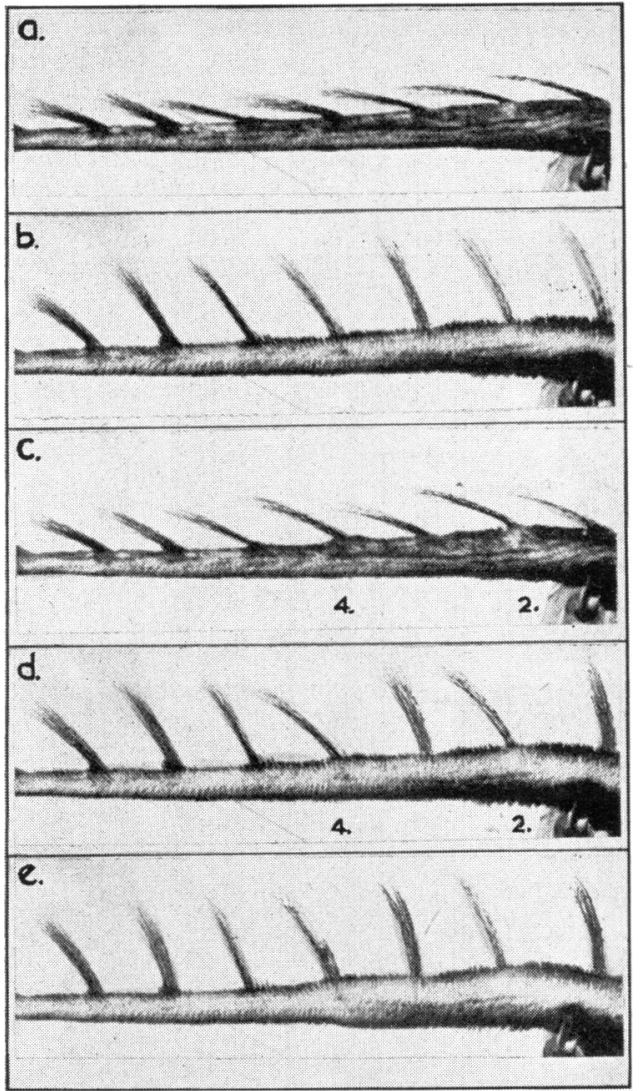

Fig. 10.-Pilomotor response in the tail of the cat $(a)$ before stimulation, $(b)$ during stimulation of night lumbar sympathetic chain, (c) after the intradermal injection of $0.2 \mathrm{mg}$. acetylcholine at the base of tufts 2 and 4 , then $(d)$ during stimulation tufts 2 and 4 were not fully erected, $(e)$ after intravenous injection of $20 \mu \mathrm{g}$. noradrenaline all tufts were erected.

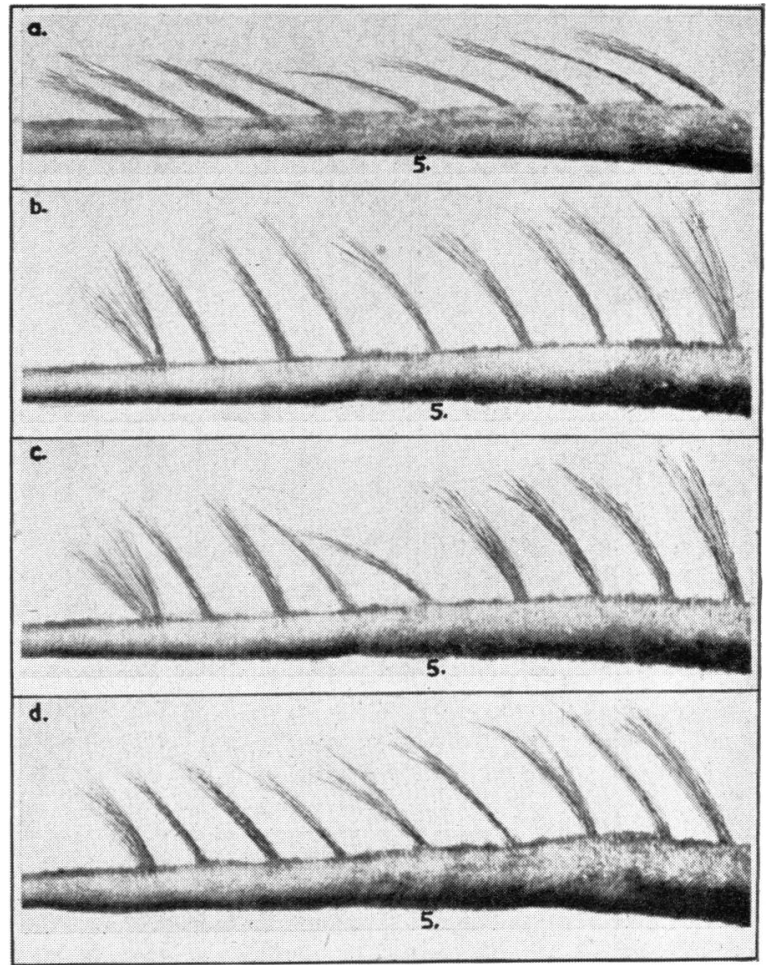

FIG. 11.-Pilomotor response in the tail of the cat. (a) Normal, (b) during sympathetic stimulation, (c) sympathetic stimulation, after intradermal injection of 0.2 mg. nicotine (base) at root of tuft 5 , failed to erect this tuft, $(d)$ intravenous injection of $30 \mu \mathrm{g}$. adrenaline caused erection of all tufts.

sympathetic stimulation, but partially blocked the effect of noradrenaline or adrenaline.

Other observations were made in the rabbit ear perfused with Locke solution by the method of Gaddum and Kwiatkowski (1938). We stimulated the postganglionic fibres and observed constriction. We observed that when acetylcholine was added to the Locke solution perfusing the ear, in concentrations from 2.5 to $20 \mu \mathrm{g} . / \mathrm{ml}$, the effect of sympathetic stimulation was blocked, but at the same time the constrictor effect of an injection of noradrenaline was reduced. Fig. 12 produces an illustration of this effect.

Observations with Choline 2,6-Xylyl Ether Bromide.-We had more success in blocking sympathetic effects with choline 2,6-xylyl ether bromide synthesized by Hey and Willey (1954) and investigated as a sympathetic blocking agent by Exley (1957). We tested its action by stimulation of the postganglionic fibres from the superior cervical ganglion both on the iris 

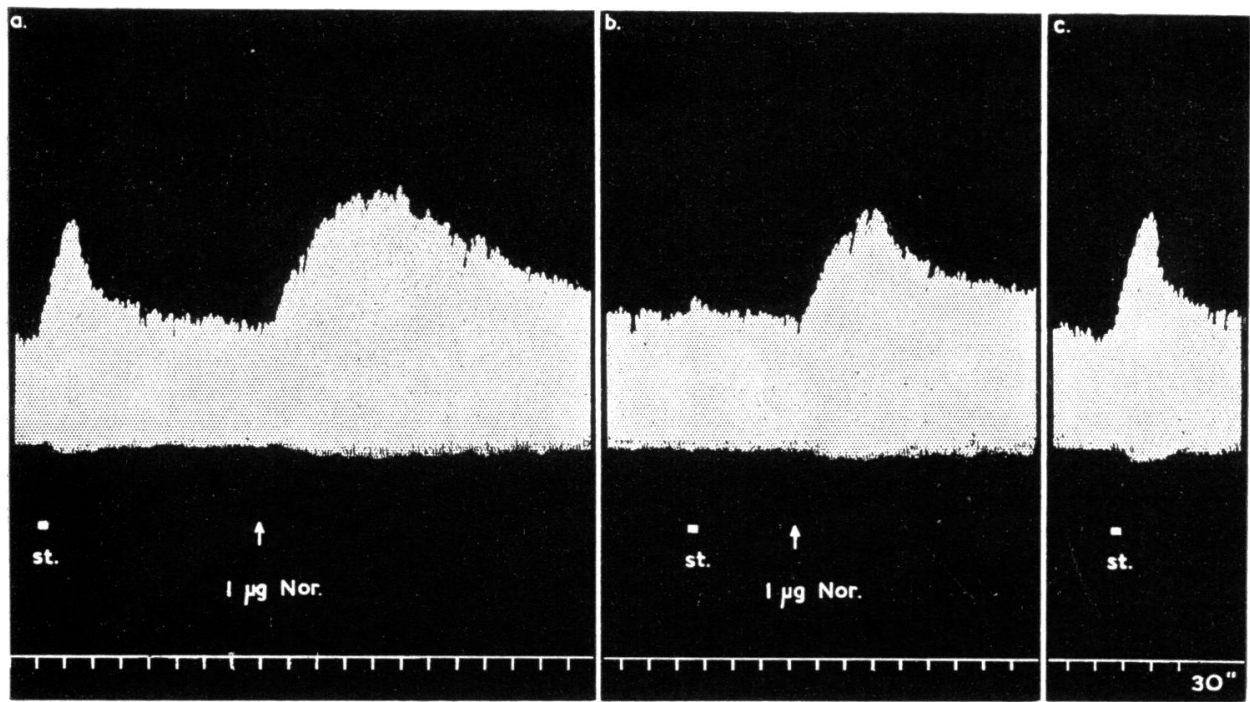

FIG. 12.-Gaddum drop-timer record of outflow from perfused rabbit ear. (a) At (st.): stimulation of postganglionic fibres caused constriction; at $(1 \mu \mathrm{g}$. Nor): injection of noradrenaline. (b) Observations when $2.5 \mu \mathrm{g} . / \mathrm{ml}$. acetylcholine was added to perfusion fluid. At (st.): stimulation was blocked; at ( $1 \mu \mathrm{g}$. Nor) : effect of injected noradrenaline was reduced. (c) At (st.) : stimulation again effective when the ear was perfused without acetylcholine.
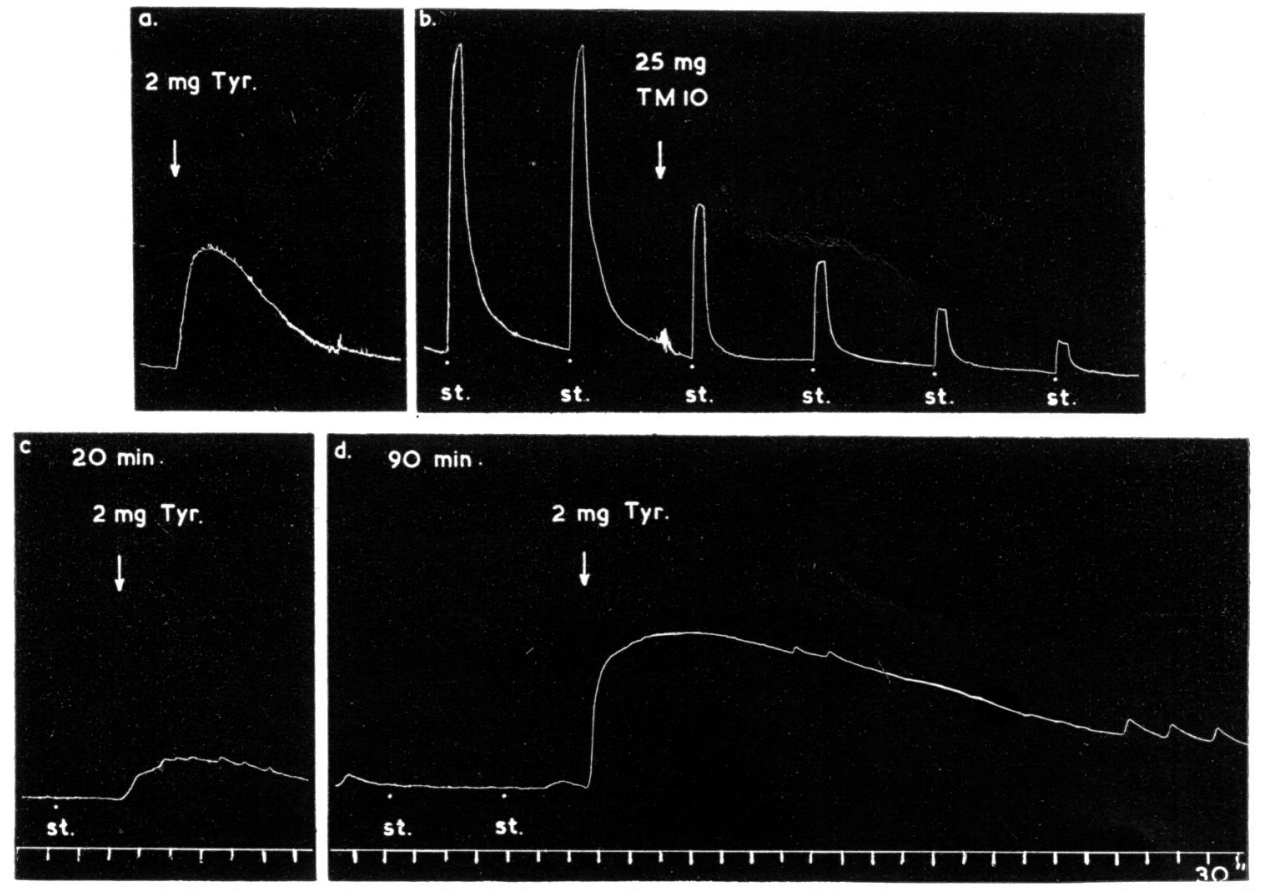

FIG. 13.-Nictitating membrane of spinal cat. (a) Intravenous injection of $2 \mathrm{mg}$. tyramine caused contraction, (b) stimulation of postganglionic fibres at $2 \mathrm{~min}$. intervals. Injection of $25 \mathrm{mg}$. choline 2,6-xylyl ether bromide (TM10) reduced the response, (c) $20 \mathrm{~min}$. after the injection of choline 2,6-xylyl ether bromide, the effect of stimulation was absent, and the effect of $2 \mathrm{mg}$. tyramine (Tyr) was reduced, (d) $90 \mathrm{~min}$. after the choline 2,6-xylyl ether bromide, stimulation was ineffective even with a 6 times stronger stimulus, and $2 \mathrm{mg}$. tyramine had a greater effect than in $(a)$. 
and on the nictitating membrane. After the injection of $10 \mathrm{mg} . / \mathrm{kg}$. stimulation soon failed to act in both organs. Fig. 13 shows an experiment on the nictitating membrane in which the response to sympathetic stimulation was compared with that to tyramine. The immediate effect of choline 2,6-xylyl ether bromide was to depress the action of tyramine, but at the end of $90 \mathrm{~min}$., when sympathetic stimulation with a strong stimulus was ineffective, the injection of tyramine produced a greater response than at first. Likewise tyramine still caused dilatation of the pupil. We also observed that the action of bretylium, $\mathrm{N}$ - $o$ - bromobenzyl - N - ethyl - NNdimethylammonium $p$-toluene-sulphonate (Boura, Green, McCoubrey, Laurence, Moulton, and Rosenheim, 1959), was essentially similar to choline 2,6-xylyl ether bromide in these respects, as shown in Fig. 14.
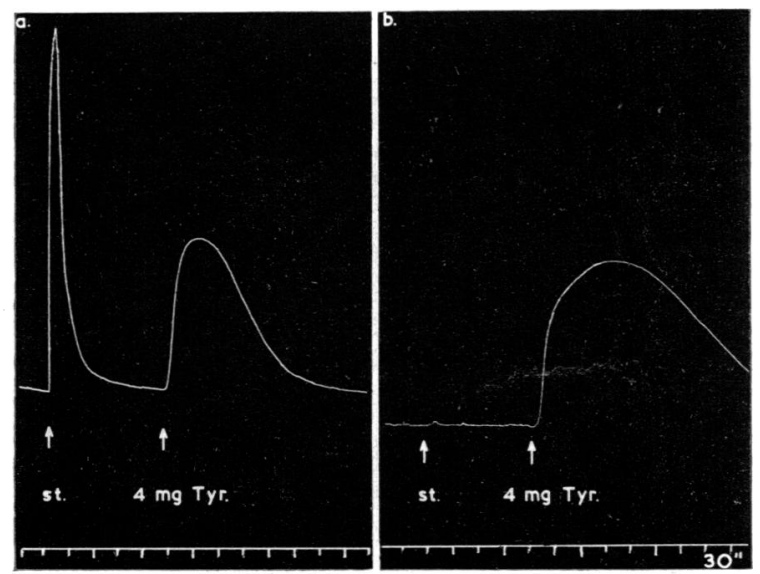

FIG. 14.-Nictitating membrane of spinal cat, $2.5 \mathrm{~kg}$. (a) Contractions due to postganglionic stimulation (st.) and to $4 \mathrm{mg}$. tyramine (Tyr.), (b) $45 \mathrm{~min}$. after injection of $25 \mathrm{mg}$. bretylium; stimulation ineffective, injection of $4 \mathrm{mg}$. tyramine had a greater effect than in $(a)$.

Our colleague Huković also tested the action of choline 2,6-xylyl ether bromide and of bretylium on the constrictor action of acetylcholine observed in the presence of atropine in the perfused rabbit ear. He found that the constrictor response to acetylcholine and that to sympathetic stimulation was abolished, while that to tyramine was greater than before. Both substances also abolished the accelerator action of acetylcholine observed in the presence of atropine, and of sympathetic stimulation in the isolated atria, but augmented the action of tyramine.

\section{Discussion}

Our previous observations (Burn and Rand, $1958 \mathrm{~b}, 1960)$ have shown that the noradrenaline which can be extracted from tissues innervated by sympathetic fibres appears to play an important part in the action of tyramine and in the effect of sympathetic stimulation. The evidence was obtained from animals given reserpine and from normal animals. If the animal was treated with reserpine the extractable noradrenaline disappeared from the vessels, and both tyramine and sympathetic stimulation were then without effect. If an intravenous infusion of noradrenaline was given, both tyramine and sympathetic stimulation had an increased action, so that the effect of the infusion did not depend on the presence of reserpine. We have supposed that the infusion of noradrenaline partly refilled the store of extractable noradrenaline or in normal animals increased it. This is, however, a supposition, for attempts to demonstrate an increase of extractable noradrenaline have not succeeded as yet (Euler, 1956b).

Now acetylcholine and nicotine in the presence of atropine have been shown to exert a variety of actions which resemble those of stimulation of the sympathetic nerves. Since they lose these actions in animals treated with reserpine they may be acting by liberating noradrenaline from the store. These actions of acetylcholine and of nicotine, which are peripheral, include (a) vasoconstriction of the vessels of the rabbit ear (Burn and Rand, 1958a), (b) acceleration of the atria of the rabbit heart (Burn and Rand, 1958c), (c) pilomotor action in the cat's tail, (d) contraction of the nictitating membrane of the cat's eye (Burn, Leach, Rand and Thompson, 1959), and (e) inhibition of the isolated uterus of the virgin bitch. Moreover, de Burgh Daly and Scott (unpublished) have observed that acetylcholine injected into the splenic artery caused contraction of the spleen. We have found that intravenous injection of acetylcholine in the cat treated with reserpine caused dilatation of the spleen. There are in addition other actions which have not yet been demonstrated to be absent in the animal treated with reserpine. Ambache and Edwards (1951) observed that nicotine in the presence of atropine caused inhibition of the isolated ileum of the kitten.

The actions of acetylcholine and nicotine not only resemble those of the sympathetic nerves, but are in some way related to them, since the actions disappear after degeneration of the sympathetic 
nerves. The constrictor action of nicotine in the perfused vessels of the rabbit ear, the pilomotor effect of nicotine and acetylcholine in the cat's tail, the contraction by nicotine of the nictitating membrane of the cat's eye, the contraction of the spleen by acetylcholine injected intra-arterially, are all lost after degeneration of the sympathetic nerves. This suggests that acetylcholine and nicotine act on part of the normal sympathetic mechanism, and it adds additional support to the suggestion that they release noradrenaline from the store near the nerve endings, since the store disappears when the sympathetic fibres degenerate (Euler and Purkhold, 1951 ; Burn and Rand, 1959).

If the store is part of the normal sympathetic mechanism and if acetylcholine can discharge noradrenaline from the store, the situation would become clarified if the postganglionic sympathetic fibres sending impulses to the store liberated acetylcholine.

Cholinergic fibres in sympathetic nerves were first demonstrated by v. Euler and Gaddum (1931) in the tongue of the dog. The classical case of a cholinergic innervation is, however, that in the sweat glands (Dale and Feldberg, 1935). Cholinergic fibres were then demonstrated in the sympathetic innervation of the vessels of the dog's hindleg (Bülbring and Burn, 1935) and in the innervation of the nictitating membrane (Bacq and Fredericq, 1935). Gaddum and Kwiatkowski (1939) observed that, in perfusions of the rabbit ear, stimulation of the great auricular and posterior auricular nerves liberated a substance in the venous effluent which caused contraction of the leech. However, they concluded that the liberation was not connected with sympathetic fibres, since the superior cervical ganglion had been removed two weeks before.

Recently Gillespie and Mackenna (1959) have found that, if rabbits were treated with reserpine, the isolated ileum was no longer inhibited by stimulation of the sympathetic fibres, but was caused to contract. The contraction was abolished by atropine, and Gillespie and Mackenna concluded that cholinergic fibres were present in the sympathetic supply. Recently also Hukovic (1959), working in this department, made a preparation of rabbit atria with sympathetic fibres attached. Stimulation of the fibres in the preparation from a normal rabbit caused acceleration of the atrial rate, but stimulation in a preparation from a rabbit treated with reserpine often caused inhibition, which was increased by eserine and abolished by atropine. He concluded that cholinergic fibres were present in the sympathetic supply.
In the present paper we have made similar observations in other tissues. Thus, in cats treated with reserpine, tyramine loses its action on the nictitating membrane altogether, but sympathetic stimulation does not; it still causes a contraction. This contraction, however, we have found is abolished by atropine. When it has been abolished or greatly reduced by atropine it can be augmented again by an infusion of noradrenaline. This suggests that the fibres which are active in stimulating the nictitating membrane in the reserpine-treated animal are cholinergic. Similarly cholinergic fibres may be present in the splenic nerve, for, in some experiments from reserpine-treated animals, stimulation of these fibres caused dilatation of the spleen, like the injection of acetylcholine. In the nictitating membrane the effects of acetylcholine released from cholinergic fibres and of noradrenaline would appear to be additive. In the spleen the effects seem to be opposed, so that in reserpinetreated animals in which stimulation of the splenic nerve still caused contraction, the contraction was greatly increased after the administration of atropine, presumably because the dilator action of acetylcholine was abolished. Cholinergic fibres also seem to be present in the sympathetic supply to the virgin cat uterus. Here again the effects of acetylcholine and those of noradrenaline (or adrenaline) appeared to be opposed ; acetylcholine causes contraction of the virgin uterus, and stimulation of the hypogastric nerves in the reserpine-treated cat was found to cause contraction also, the contraction being increased by eserine and abolished by atropine. Thus a normally inhibitory sympathetic nerve supply seems to contain cholinergic fibres. Koelle (1955) from histochemical studies found that "there is probably some representation of typical cholinergic fibres in practically all predominantly adrenergic and sensory nerves." $\mathrm{He}$ went on to ask whether the terms cholinergic and adrenergiz might refer to the predominant rather than to the exclusive types of transmitting agents of the nerve fibres.

Three observations respecting the postganglionic mechanism may now be considered together. First that the effect of sympathetic stimulation can be increased by infusing noradrenaline into the blood. Second that acetylcholine (after atropine), by a nicotine-like action exerted at the periphery, can reproduce sympathetic effects, and that it does so by causing a release of noradrenaline from the store at the nerve endings since it no longer acts when the sympathetic fibres have degenerated, or in the animal treated with reserpine. Third that 
cholinergic fibres seem to be present wherever they are looked for in sympathetic fibres.

These observations at once suggest a function for the cholinergic fibres present in the sympathetic supply to organs like the spleen. The cholinergic fibres are probably adrenergic in effect, since the acetylcholine they discharge will act on the store of noradrenaline and liberate noradrenaline from it. This idea serves to explain an observation previously made by one of us (Burn, 1932) and illustrated in J. Physiol. (vol. 75, p. 150). There has hitherto been no explanation for it. When the lumbar sympathetic chain was stimulated during perfusion of the hindleg of a dog, a stimulus of $3 \mathrm{sec}$. duration caused a fall in arterial resistance. When the same stimulus was applied for $30 \mathrm{sec}$. the main effect was a rise in arterial resistance. It appeared that in stimulating for 3 sec. vasodilator fibres were excited, while in stimulating for $30 \mathrm{sec}$. vasoconstrictor fibres were excited. It may now be suggested that the $3 \mathrm{sec}$. stimulation resulted in a release of acetylcholine and a fall of arterial resistance due to the direct action of this substance; the $30 \mathrm{sec}$. stimulation resulted in a more prolonged release of acetylcholine, which was enough to liberate noradrenaline from the store. The usual conception of adrenergic fibres is that they are fibres directly liberating noradrenaline. We now have a second conception, namely, that fibres liberating acetylcholine may, by doing so, discharge noradrenaline from the store.

The cholinergic fibres may be blocked by excessive amounts of acetylcholine, as Brücke (1935) first showed in the pilomotor muscles of the cat's tail, and as we have seen in the vessels of the rabbit ear. The action of the blocking agents choline 2,6-xylyl ether bromide and of bretylium may be similar. These substances block sympathetic impulses completely, but do not prevent the action of tyramine. Indeed, $1 \mathrm{hr}$. after giving choline 2,6-xylyl ether bromide or bretylium, the action of tyramine is increased. Choline 2,6-xylyl ether bromide and bretylium, which block not only sympathetic stimulation but also the action of acetylcholine in producing sympathetic effects, seem well suited from their structure to prevent the action of sympathetic fibres from releasing noradrenaline from the store.

At the present time we have nothing more than hints on the site of the store and we mention them only to indicate directions in which further research might be made. v. Euler (1956) has expressed the view that the noradrenaline present in the spleen is probably within the fine termina- tions of the nerves since there is no evidence that it is located outside the nervous tissue itself. He calculated that the amount present would be from 3 to $30 \mathrm{mg}$. $/ \mathrm{g}$., though the amount in the nerves before they reach the spleen is (in the ox) about $15 \mu \mathrm{g}$. $/ \mathrm{g}$. If the store is located as v. Euler suggests, then the fine nerve terminals must be able to take up noradrenaline from the circulating blood. The fact that the store disappears when the nerves degenerate is consistent with the view that the store is within the nerves. On the other hand the fact that acetylcholine injected into the splenic artery can release noradrenaline from the store might indicate that the store is outside the nerves. It is conceivable that the store is held in chromaffin cells which have been described by Nordenstam and Adams-Ray (1957) and confirmed by Burch and Phillips (1958) in human skin, and have been observed by Leach (see Burn and Rand, 1958a) in the skin of the rabbit ear. They have also been observed in the cat's nictitating membrane and in the skin of the cat's tail (Burn, Leach, Rand, and Thompson, 1959). These cells disappeared in animals treated with reserpine, and in the nictitating membrane they also disappeared after degeneration of the sympathetic fibres. Much further work is, however, required to connect them with the store.

Our observations raise questions about the postganglionic sympathetic fibres, though they cannot be answered at present. Since the evidence for purely adrenergic fibres is very strong [obtained from histochemical examination of sympathetic ganglia (Koelle and Koelle, 1959) as well as from chemical identification of noradrenaline, dopamine and dopa decarboxylase in the fibres (Schümann, 1958)], there appear to be two mechanisms by which noradrenaline is released. The first is by simple release from the adrenergic fibres, and the second by the action of cholinergic fibres releasing noradrenaline from the store. These mechanisms seem fundamentally different, and it is, therefore, surprising that they should exist side by side; it is further surprising that both should be blocked by choline 2,6-xylyl ether bromide and by bretyllium.

Another question concerns the cholinergic fibres. Do some of these liberate acetylcholine to act directly, and others liberate it to set free noradrenaline from a store? The sweat glands are stimulated by the release of acetylcholine, but the cholinergic fibres to the muscle vessels of the dog's hindleg may certainly prove to be fibres whose main function is to release noradrenaline from a store, since in many dogs vasodilator 
effects of stimulation are not seen unless special steps (such as the use of eserine) are taken to unmask them.

A conception which might unify the observations is that sympathetic postganglionic fibres were, like the other peripheral efferent fibres, originally cholinergic. In the course of evolution, for the purpose of developing an adrenergic mechanism, they came to innervate a store of noradrenaline, perhaps present in chromaffin tissue, so that the innervation in some respects resembled that of the adrenal medulla. In further development, the fibres were modified so that the noradrenaline in the chromaffin tissue was developed in the fibre itself, the true adrenergic fibres thus being formed. The blocking action of bretylium may, however, indicate that even these still possess some kind of cholinergic background. Thus postganglionic fibres may contain representatives of the three stages of development, the proportion varying according to the tissue innervated and perhaps according to the species.

This work was done during the tenure by one of us (M. J. R.) of a Fellowship from the Life Insurance Medical Research Fund of Australia and New Zealand.

\section{REFERENCES}

Ambache, N., and Edwards, J. (1951). Brit. J. Pharmacol., 6, 311.

Bacq, Z. M., and Fredericq, H. (1935). Arch. int. Physiol., 40, ?.97.
Boura, A. L. A., Green, A. F., McCoubrey, A., Laurence, D. R., Moulton, R., and Rosenheim, M. L. (1959). Lancet, 2, 17.

Brücke, F. T. (1935). Klin. Wschr., 14, 7.

Bülbring, E., and Burn, J. H. (1935). J. Physiol. (Lond.), $83,483$.

Burch, G. E., and Phillips, J. H. (1958). Circulat. Res., 6, 416.

Burn, J. H. (1932). J. Physiol. (Lond.), 75, 144.

(1952). Practical Pharmacology. Oxford: Blackwell. Leach, E. H., Rand, M. J., and Thompson, J. W. (1959). J. Physiol. (Lond.), 148, 332.

-_ and Rand, M. J. (1958a). Brit. med. J., 1, 903.

__ _ (1958b). J. Physiol. (Lond.), 144, 314. (1958c). Brit. med. J., 1, 137.

__ (1959). J. Physiol. (Lond.), 147, 135.

- (1960). Ibid., 150. In the press.

Dale, H. H., and Feldberg, W. (1935). Ibid., 82, 121.

Euler, U. S. v. (1956a). Noradrenaline. Springfield, Illinois: C. C. Thomas.

-_ (1956b). Circulat. Res., 4, 647. and Gaddum, J. H. (1931). J. Physiol. (Lond.), 73, 54.

and Purkhold, A. (1951). Acta physiol. scand., 24, 212.

Exley, K. A. (1957). Brit. J. Pharmacol., 12, 297.

Gaddum, J. H., and Kwiatkowski, H. (1938). J. Physiol. (Lond.), 94, 87.

_- (1939). Ibid., 96, 385.

Gillespie, J. S., and Mackenna, B. R. (1959). Ibid., 147, $31 \mathrm{P}$.

Hey, P., and Willey, G. L. (1954). Brit. J. Pharmacol., 9, 471 .

Hukovič, S. (1959). Ibid., 14, 372.

Koelle, G. B. (1955). J. Pharmacol. exp. Ther., 114, 167. Koelle, W. A., and Keolle, G. B. (1959). Ibid., 126, 1.

Nordenstam, H., and Adams-Ray, J. (1957). $Z$. Zellforsch., 45, 435 .

Schümann, H. J. (1958). Arch. exp. Path. Pharmak., 234, 17 . 